\title{
Unconjugated bilirubin and schizophrenia: a systematic review - Corrigendum
}

\section{Erik Pommerening Dornelles, João Gama Marques, and Sílvia Ouakinin}

DOI: https://doi.org/10.1017/S109285291800161X. Published by Cambridge University Press 27 March 2019.

The original publication of this article (Pommerening Dornelles et al.), contained an error in Table 1. The Table 1 is now reproduced correctly below.

The authors regret this error.

\section{REFERENCE:}

Pommerening Dornelles, E., Gama Marques, J., \& Ouakinin, S. Unconjugated bilirubin and schizophrenia: A systematic review. CNS Spectrums, 1-12. doi: 10.1017/S109285291800161X. Published online 27 March 2019.

\begin{tabular}{|c|c|c|c|c|}
\hline Authors (year) & Sample & $\begin{array}{l}\text { UCB or BOMs mean levels in } \\
\text { schizophrenia patients }\end{array}$ & After treatment & Clinical \\
\hline $\begin{array}{l}\text { Miyaoka et al. } \\
\text { (2000) }\end{array}$ & $\begin{array}{l}\mathrm{N}=290 \\
\text { humans }\end{array}$ & High UCB. & $\begin{array}{l}\text { Decreased } \\
\text { UCB. }\end{array}$ & $\begin{array}{c}\text { Positive correlation with Positive symptoms } \\
\text { on PANSS scores. }\end{array}$ \\
\hline $\begin{array}{l}\text { Miyaoka et al. } \\
\text { (2005) }\end{array}$ & $\begin{array}{l}\mathrm{N}=15 \\
\text { humans }\end{array}$ & High BOMs. & - & Positive correlations with BPRS scores. \\
\hline $\begin{array}{l}\text { Yasukawa et al. } \\
\text { (2007) }\end{array}$ & $\begin{array}{l}\mathrm{N}=15 \\
\text { humans }\end{array}$ & High BOMs. & $\begin{array}{l}\text { Decreased } \\
\text { BOMs. }\end{array}$ & - \\
\hline $\begin{array}{l}\text { Miyaoka et al. } \\
\text { (2008) }\end{array}$ & $\begin{array}{l}\mathrm{N}=290 \\
\text { humans }\end{array}$ & High UCB. & - & $\begin{array}{l}\text { Positive correlation with PANSS scores during } \\
\text { acute phases. }\end{array}$ \\
\hline $\begin{array}{l}\text { Hayashida et al. } \\
\text { (2009) }\end{array}$ & $\begin{array}{l}\mathrm{N}=10 \\
\text { Gunn rats }\end{array}$ & High UCB. & - & $\begin{array}{l}\text { Positive correlation with impaired PPI and } \\
\text { stereotypical behaviors. }\end{array}$ \\
\hline $\begin{array}{l}\text { Semnani et al. } \\
\text { (2010) }\end{array}$ & $\begin{array}{l}\mathrm{N}=162 \\
\text { humans }\end{array}$ & $\begin{array}{l}\text { Normal UCB, but higher vs. } \\
\text { bipolar patients. }\end{array}$ & $\begin{array}{l}\text { Decreased } \\
\text { UCB. }\end{array}$ & Positive correlation with PANSS scores. \\
\hline $\begin{array}{l}\text { Radhakrishnan } \\
\text { et al. (2011) }\end{array}$ & $\begin{array}{l}\mathrm{N}=71 \\
\text { humans }\end{array}$ & $\begin{array}{l}\text { Normal UCB, but higher vs. } \\
\text { bipolar patients. }\end{array}$ & $\begin{array}{l}\text { No significant } \\
\text { change. }\end{array}$ & - \\
\hline Liaury et al. (2012) & $\begin{array}{l}\mathrm{N}=10 \\
\text { Gunn rats }\end{array}$ & High UCB. & - & $\begin{array}{l}\text { Positive correlation with Iba1, CD11b marked } \\
\text { hippocampus cells. }\end{array}$ \\
\hline $\begin{array}{l}\text { Tsuchie et al. } \\
\text { (2013) }\end{array}$ & $\begin{array}{l}\mathrm{N}=6 \text { Gunn } \\
\text { rats }\end{array}$ & High UCB. & - & $\begin{array}{l}\text { Improvement in hyperactivity and social } \\
\text { behaviors after treatment. }\end{array}$ \\
\hline $\begin{array}{l}\text { Miyaoka et al. } \\
\text { (2015) }\end{array}$ & $\begin{array}{l}\mathrm{N}=29 \\
\text { humans }\end{array}$ & High BOMs. & - & Positive correlation with BPRS scores. \\
\hline $\begin{array}{l}\text { Gama-Marques } \\
\text { et al. (2017) }\end{array}$ & $\begin{array}{l}\mathrm{N}=50 \\
\text { humans }\end{array}$ & $\begin{array}{l}\text { Normal UCB, but higher vs. } \\
\text { bipolar patients. }\end{array}$ & - & - \\
\hline
\end{tabular}

BOMs = Bilirubin Oxidative Metabolites (urine); BPRS = Brief Psychiatric Rating Scale; PANSS = Positive And Negative Syndrome Scale; $\mathrm{PPI}=$ Prepulse Inhibition test $\mathrm{UCB}=$ Unconjugated Bilirubin (plasma). 